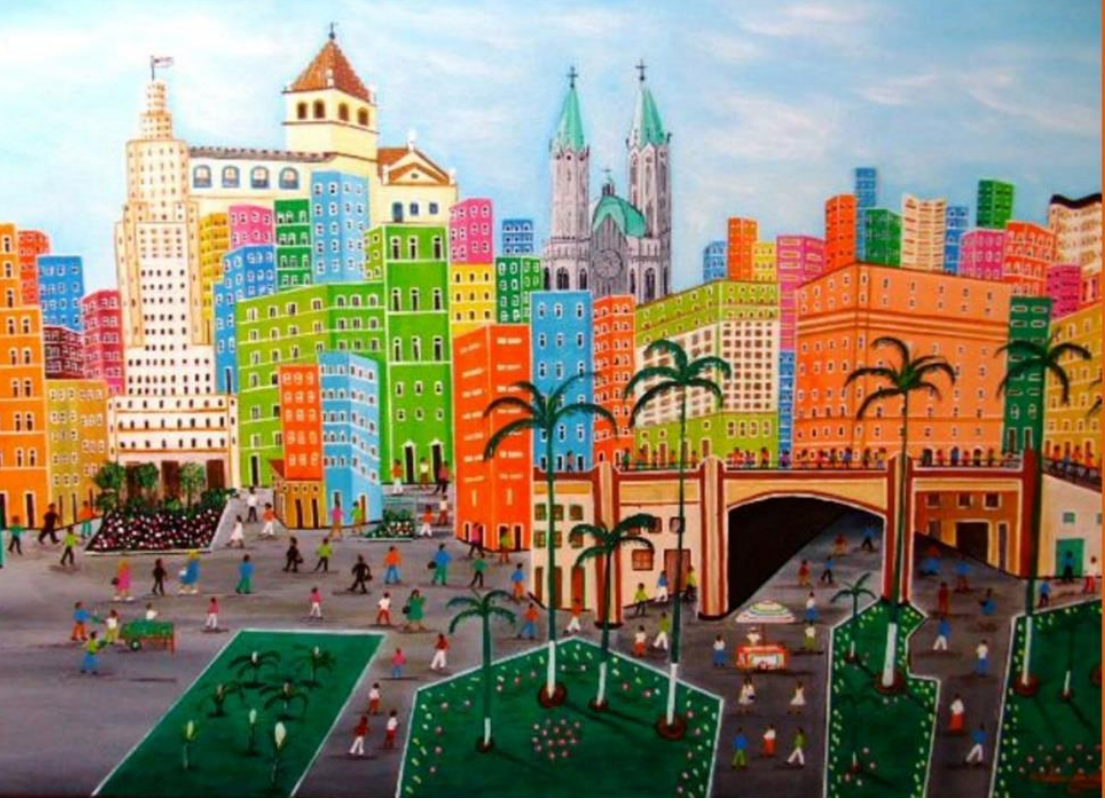

revista eletrônica do netlli volume 6, número 1, Jan.-Abr. 2017

\title{
O ENSINO DE LÍNGUA PORTUGUESA E SUAS ABORDAGENS: UMA RELAÇÃO TEORIA E PRÁTICA
}

\author{
PORTUGUESE LANGUAGE TEACHING AND ITS \\ APPROACHES: A THEORY AND PRACTICAL \\ RELATIONSHIP
}

\author{
Lucas Saldanha da CRUZ \\ UNIVERSIDADE FEDERAL DE SANTA MARIA, Brasil
}

RESUMO | INDEXAÇÃO | TEXTO | REFERÊNCIAS | CITAR ESTE ARTIGO | O AUTOR

RECEBIDO EM 25/01/2017 • APROVADO EM 25/04/2017

\section{Abstract}

The present article presents theories that support the teaching of Portuguese Language with regard to written production and work with argumentation, reflecting on the difficulties and possibilities found in the Supervised Internship in Portuguese High School. The theories are basically the procedural approach of writing, presented by Soares (2009), the question of textual genres treated by Marcuschi (2008) and Dolz \& Schneuwly (2004), the argument brought by Abreu (2008) and Bernardo (2000), The portfolio treated by Motta (2009) and the grammatical questions by Travaglia (2006). It was understood that such theories are perfectly applicable in the classroom. 
Resumo

O presente artigo apresenta teorias que embasam o ensino de Língua Portuguesa no que diz respeito à produção escrita e trabalho com argumentação, refletindo sobre as dificuldades e possibilidades encontradas no Estágio Supervisionado no Ensino Médio em Português. As teorias são, basicamente, a abordagem processual da escrita, apresentada por Soares (2009), a questão dos gêneros textuais tratada por Marcuschi (2008) e Dolz; Noverraz e Schneuwly (2004), a argumentação trazida por Abreu (2008) e Bernardo (2000), o portfólio tratado por Motta (2009) e as questões gramaticais por Travaglia (2006). Compreendeu-se que tais teorias são perfeitamente aplicáveis em sala de aula.

Entradas para indexação

Keywords: Writing. Argumentation. Genres.

Palavras-chave: Escrita. Argumentação. Gêneros.

\section{Texto integral}

\section{CONTEXTUALIZAÇÃO}

Argumentar é uma ação que se inicia desde a infância, quando queremos algo e tentamos persuadir nossos pais por meio das palavras ou gestos e ela acompanha o ser humano durante toda a vida. Na mídia, por exemplo, há diversos gêneros argumentativos, como por exemplo a carta do leitor e o artigo de opinião.

Ao se considerar que há uma complexidade na produção de textos argumentativos e toda a necessidade da argumentação na vida de qualquer pessoa, percebe-se que a escola tem uma importância fundamental no processo de aprendizagem das técnicas argumentativas e no desenvolvimento da organização retórica em produções escritas.

Assim, esse estudo é um importante instrumento de trabalho em sala de aula, principalmente no Ensino Médio, quando os alunos precisam ser capazes de atuar plenamente na sociedade. Outro fator importante é a presença de vários gêneros argumentativos que circulam na sociedade em que os estudantes atuam. 0 presente artigo apresenta o resultado do projeto de estágio $A$ argumentação a partir dos gêneros textuais carta do leitor e artigo de opinião aplicado em uma turma de $2^{\circ}$ ano do Ensino Médio de uma escola pública de Santa Maria1.

Este trabalho, portanto, apresenta uma proposta de ensino-aprendizagem que envolve a argumentação no Ensino Médio, partindo dos gêneros carta do leitor e artigo de opinião. Inicialmente, são apresentadas teorias que embasam essa 
proposta, após segue o relato da prática e então os pontos convergentes pensando na relação entre a teoria e a prática.

\section{EMBASAMENTO TEÓRICO}

Esta seção apresenta a base teórica deste artigo que serviu como suporte na realização do estágio supervisionado. São discutidas questões referentes à linguagem, à abordagem processual da escrita, aos gêneros textuais, à argumentação e o ensino de língua, ao portfólio como produto final e às questões gramaticais.

Primeiramente, apresenta-se como a linguagem é entendida e de que forma foi abordada a escrita.

\subsection{A linguagem e a abordagem processual da escrita}

A concepção de linguagem utilizada vai ao encontro do que é proposto por Geraldi, o qual entende a linguagem como uma forma de interação em que:

Mais do que possibilitar uma transmissão de informações de um emissor a um receptor, a linguagem é vista como um lugar de interação humana. Por meio dela, o sujeito que fala pratica ações que não conseguiria levar a cabo, a não ser falando; com ela o falante age sobre o ouvinte, constituindo compromissos e vínculos que não preexistem à fala. (GERALDI, 1997, p. 41).

A partir dessa ideia, compreende-se ser necessário entender a linguagem como um princípio de interação e não apenas como uma simples troca de mensagens entre emissor e receptor.

Com relação à escrita, busca-se referência em Soares (2009) a qual apresenta três estágios pelos quais podemos trabalhar no processo de escrita, conforme o quadro 1:

\begin{tabular}{|c|l|}
\hline Estágio & \multicolumn{1}{|c|}{ Descrição } \\
\hline Pré-escrita & $\begin{array}{l}\text { São apresentadas aos alunos atividades para se } \\
\text { descobrir maneiras de abordar a tarefa, investigar o } \\
\text { contexto, além de coletar informações e gerar ideias. }\end{array}$ \\
\hline Escrita do texto & $\begin{array}{l}\text { Há o registro escrito organizado de ideias e } \\
\text { informações }\end{array}$ \\
\hline
\end{tabular}




\begin{tabular}{|c|l|}
\hline Revisão ou pós- escrita & $\begin{array}{l}\text { Realização de atividades que incluem leitura e } \\
\text { avaliação do que foi escrito a partir do recebimento } \\
\text { de feedback do professor. }\end{array}$ \\
\hline
\end{tabular}

Quadro 1- Estágios do processo de escrita.

Ainda, segundo a mesma autora, com esse processo, desenvolvem-se habilidades como:

- avaliar nossos conhecimentos para determinar o que é conhecimento compartilhado e o que é exclusivamente nosso;

- decidir como organizar a informação para alcançar nosso propósito com o texto (relatar uma experiência, convencer alguém de uma opinião, persuadir alguém a fazer o que queremos, descrever algo para alguém;

- julgar se nossas escolhas linguísticas produzem o sentido que queremos para expressar a mensagem em sua totalidade;

- certificarmo-nos de que o leitor será capaz de seguir a linha de raciocínio que perpassa todo o texto.

Ainda sobre a reescrita, considera-se que foi uma atividade imprescindível no estágio, sendo uma tarefa indispensável para que o aluno possa repensar sua produção de texto e tentar melhorá-la cada vez mais. Essa ideia está baseada no trecho de Dolz; Noverraz e Schneuwly (2004, p. 112) em que afirmam:

[...] e escritor pode considerar seu texto como um objeto a ser retrabalhado, revisto, refeito, mesmo a ser descartado, até o momento em que o dá a seu destinatário. 0 texto permanece provisório enquanto estiver submetido a esse trabalho de reescrita. Podemos até dizer que considerar seu próprio texto como objeto a ser retrabalhado é um objetivo essencial do ensino da escrita. 0 aluno deve aprender que escrever é (também) reescrever.

Na reescrita, portanto, é possibilitado que o aluno reflita sobre a sua escrita, diante da possibilidade de melhorá-la, podendo alterar aquilo que não ficou claro, os problemas de conteúdo e gramaticais. Enfim, esse processo possibilita ao aluno um momento de reflexão sobre a sua própria produção. Consiste, assim, no momento em que o estudante tem a oportunidade de compreender melhor o processo de escrita, entendendo que, dificilmente, um texto ficará satisfatório em uma primeira versão.

Entendida como a linguagem é abordada e como se deu o processo de escrita, a seguir, apresenta-se uma discussão acerca dos gêneros textuais. 


\subsection{Os gêneros textuais}

Em relação à questão de gêneros textuais, entende-se que trabalhar com essa teoria em sala de aula é relevante para compreender a língua nos mais diversos usos do cotidiano. E, pensando ainda sobre essa questão é importante lembrar a proposta de Dolz; Noverraz e Schneuwly (2004) a qual propõe o agrupamento de gêneros, que consiste em organizá-los de acordo com as semelhanças das situações de produção.

Ainda, em se tratando disso, é importante fazer alusão aos trabalhos de Marcuschi, o qual define os gêneros com uma natureza sociocomunicativa, baseando-se nos usos e nos discursos existentes. Os gêneros textuais, portanto, são textos que se realizam empiricamente e que encontramos socialmente materializados com uma situação de tempo e de espaço.

Para o estágio em questão, foram estudados e produzidos a carta do leitor e o artigo de opinião. Quanto à carta do leitor, tem-se a seguinte citação de Bezerra (2010, p. 232):

Se eles (os alunos) não têm experiência com a leitura de cartas, é interessante iniciar pela discussão do que são cartas, quais suas funções, a quem se destinam e de que temas tratam. E, em seguida, ler cartas com o mesmo tema, para comparar sua organização: posição enunciativa do autor, variedade linguística, sequências textuais, seleção lexical e outros aspectos.

Percebe-se assim, que é relevante partir da apresentação do gênero aos alunos, para construir um aprendizado significativo e, em seguida, trazer cartas que tratem do mesmo assunto para se notar as peculiaridades em relação à linguagem e compreender a variedade de formas de se fazer uma carta do leitor.

Em se tratando de artigo de opinião, Cunha (2010), ao pensar na relação dialógica existente nesse gênero, afirma que o mesmo traz o ponto de vista de um jornalista ou colaborador do jornal, utilizando dêiticos, presente do indicativo como tempo base e a presença clara da argumentação. A autora afirma ainda, que esse gênero sempre comenta algo já dito, sendo então, um gênero de "enunciação subjetiva" (MOIRAND, 1999, p. 57).

\subsection{A argumentação e o ensino de língua}

Com relação à argumentação, pode-se dizer que ela está presente na maioria dos discursos. Fazemos uso dela constantemente, desde criança argumentamos. Torna-se importante, primeiramente entender o que é argumentar: 
Argumentar é a arte de convencer e persuadir. Convencer é saber gerenciar informação, é falar à razão do outro, demonstrando, provando. Etimologicamente, significa vencer junto com o outro (com + vencer) e não contra o outro. Persuadir é saber gerenciar relação, é falar à emoção do outro. A origem dessa palavra está ligada à preposição per, "por meio de" e a Suada, deusa romana da persuasão. Significava "fazer algo por meio do auxílio divino". Mas em que convencer se diferencia de persuadir? Convencer é construir algo no campo das ideias. Quando convencemos alguém, esse alguém passa a pensar como nós. Persuadir é construir no terreno das emoções, é sensibilizar o outro para agir. Quando persuadimos alguém, esse alguém realiza algo que desejamos que ele realize. (ABREU, 2008, p. 9).

Portanto, argumentar é algo que necessitamos todos os dias, nas relações com as pessoas. Para nos consolidarmo-nos como cidadãos plenos, precisamos utilizar dos artifícios da argumentação, uma vez que:

o ensino médio deve atuar de forma que garanta ao estudante a preparação básica para o prosseguimento dos estudos, para a inserção no mundo do trabalho e para o exercício cotidiano da cidadania, em sintonia com as necessidades político-sociais de seu tempo. (BRASIL, 2006, p. 18).

Com relação ao histórico da argumentação, afirma-se que a retórica surgiu na Grécia antiga, por volta de 427 a.C. em um período em que os atenienses viviam os primeiros passos da democracia. Nesse momento, era muito importante que os cidadãos tivessem o domínio do bem falar e argumentar, nas assembleias e tribunais.

Desde então, a arte de argumentar vem se difundindo nas interações humanas e, como afirma Bernardo (2000), a interação e a capacidade crítica na aprendizagem é desencadeada pela argumentatividade. 0 aluno precisa compreender o que é argumentar para desenvolver um senso crítico e não acreditar em tudo o que ouve.

Considerando que, segundo Geraldi (1997, p. 41), “a linguagem é uma forma de interação", é extremamente importante o professor de Língua Portuguesa trabalhar com a argumentação em sala de aula, apresentando os gêneros textuais que a utilizam. Pensa-se assim, pois saber argumentar consiste em um artifício relevante para qualquer cidadão o qual precisa ter opinião formada.

Na sequência, discute-se a questão do portfólio de produções textuais como produto final do estágio supervisionado. 


\subsection{0 portfólio como produto final}

Por portfólio, entende-se, conforme Harp e Huinsker (1997 apud MOTTA, 2009), uma coletânea de trabalhos que demonstra o desenvolvimento da escrita, as competências e habilidades de um indivíduo, em um determinado tempo. Ele é, portanto, um importante instrumento para que o aluno seja capaz de refletir sobre as suas próprias produções e aperfeiçoar sua escrita.

Ainda sobre isso, cabe ressaltar que, como já afirmado, promove a autorreflexão do aluno, que é fundamental para que o aluno possua mais autonomia em relação a sua produção.

$\mathrm{Na}$ sequência são discutidas questões referentes ao estudo gramatical em sala de aula.

\subsection{Auestões gramaticais}

Travaglia (2006) apresenta uma proposta para o ensino de gramática acreditando que ensinar a língua materna é priorizar o desenvolvimento da competência comunicativa, além disso, buscar a aquisição de novas habilidades linguísticas. Também, para essa abordagem de ensino de gramática, entende-se a linguagem como forma de interação. A proposta do autor que será apresentada neste artigo é a gramática reflexiva, em que é afirmado:

[...] não concordamos que a gramática reflexiva seja só um trabalho de reflexão sobre o que o aluno já domina, mas também um trabalho sobre os recursos linguísticos que ele ainda não domina, para levá-lo à aquisição de novas habilidades linguísticas, realizando assim um ensino produtivo e não apenas de descrição. (TRAVAGLIA, 2006, p.142).

Essa gramática, portanto, não se prende apenas à prescrição das regras, mas sim à reflexão. 0 professor não apenas ensina as regras gramaticais, mas também leva o aluno a refletir sobre a estrutura e o funcionamento da língua, utilizando por exemplo, a semântica e a pragmática, que muitas vezes são esquecidas nas aulas de Língua Portuguesa.

\section{RELATO DA PRÁTICA}

A prática de estágio na turma já referida anteriormente aconteceu no período de 04 de setembro a 04 de dezembro de 2013, com a carga-horária de 2 h semanais. Antes da prática, houve o período de observação em que se pode constatar que os 
alunos demonstravam-se muito críticos em relação aos acontecimentos atuais, por isso, pensou-se em trabalhar com a argumentação.

Foi necessário partir do início, com o conceito de argumentação, pois alguns alunos, no questionário investigativo, demonstraram não ter bem claro o que efetivamente é a argumentação. Na primeira aula, foi mostrado aos alunos um vídeo intitulado $O$ poder da argumentação, em que era possível perceber qual a finalidade da argumentação. Após, os alunos opinaram sobre o vídeo e então, no quadro, foi construído, conjuntamente, o conceito de argumentação. Além disso, nessa mesma aula, houve um levantamento de que momentos da nossa vida utilizamos a argumentação e algumas estratégias argumentativas.

Nessa primeira aula, ao final, solicitou-se que os alunos fizessem um texto dissertativo-argumentativo sobre a realização da Copa do Mundo de futebol no Brasil e se posicionassem. Esse texto serviu como uma produção para diagnosticar as dificuldades dos alunos na escrita.

Nas aulas seguintes, procurou-se tratar dos tipos de argumentos que podemos utilizar para atingir nossos objetivos argumentativamente e, também, os gêneros argumentativos, com a caracterização de cada um, escrita, reescrita e automonitoramento da própria escrita.

Com relação ao trabalho da argumentação, pode-se dizer que foi relevante, pois os alunos se posicionaram bastante em aula e debateram sobre os assuntos que foram levados, como a Copa do Mundo de 2014 no Brasil, a espionagem norteamericana ao Brasil e as manifestações ocorridas no Brasil em julho de 2013.

No que se refere à escrita e reescrita dos gêneros estudados, o trabalho foi satisfatório, pois os alunos já possuíam um bom domínio do processo de escrita (com raras exceções) e puderam aperfeiçoar ainda mais. Quanto à escrita da carta do leitor, a dificuldade se deu, principalmente na questão estrutural, enquanto na parte da argumentação, os alunos se posicionaram de forma que seus pontos de vista de forma contundente. Ainda sobre a carta do leitor, cabe ressaltar que utilizou--se a estratégia de automonitoramento, que deu um grande avanço na reescrita, pois os alunos puderam refletir sobre a sua produção e reescrever observando o que precisava melhorar.

$\mathrm{Na}$ escrita do artigo de opinião, alguns alunos, ao não entender a caracterização do gênero, escreveram como se fosse uma redação de vestibular. Na parte argumentativa, também foram muito contundentes em seus argumentos. Além disso, foi realizada a reescrita do artigo de opinião, em que se pode perceber um grande avanço. Na imagem 1, há um exemplar de texto produzido e na imagem 2 um demonstrativo de como se deu o recebimento do texto ao aluno. 


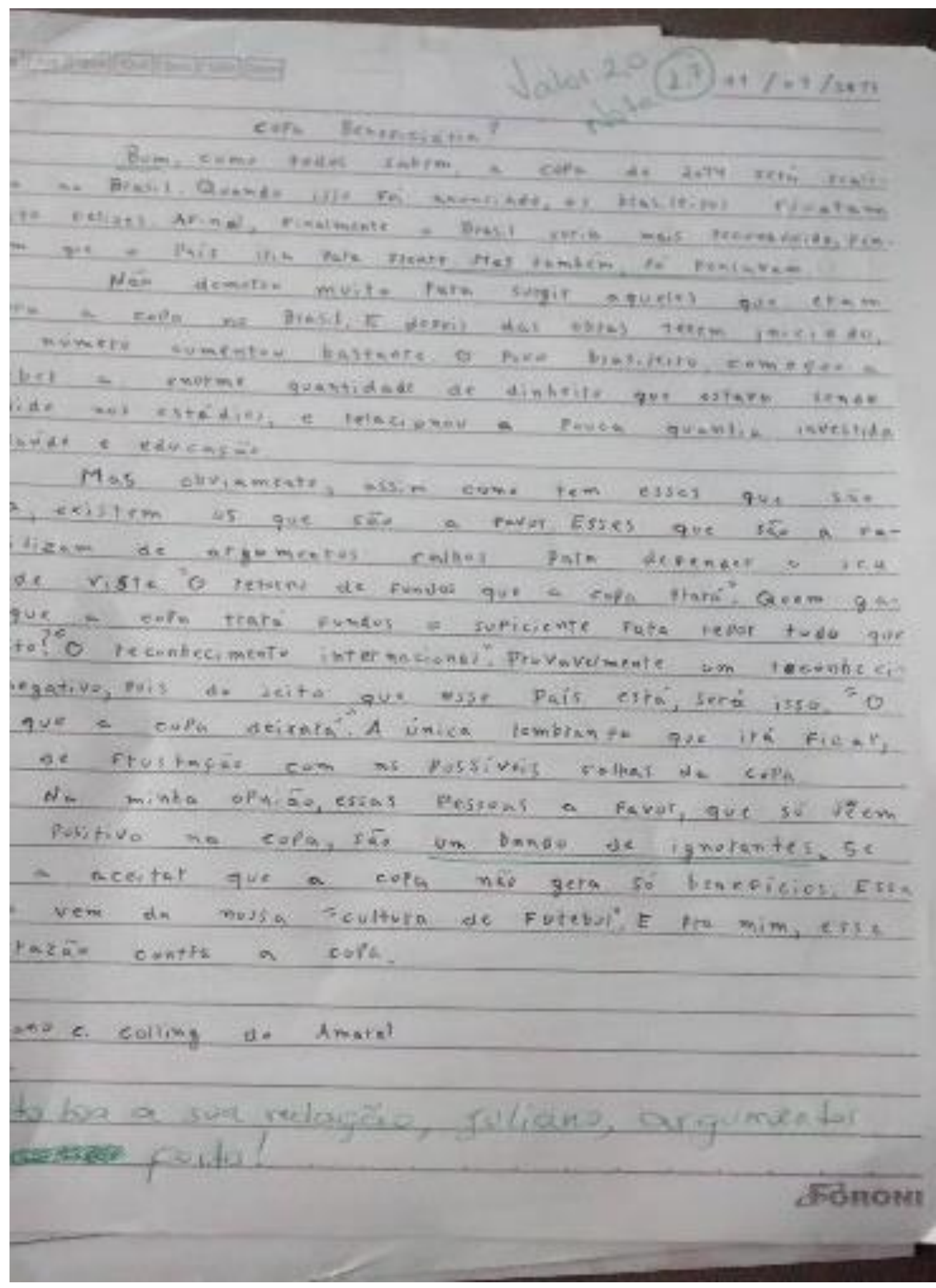




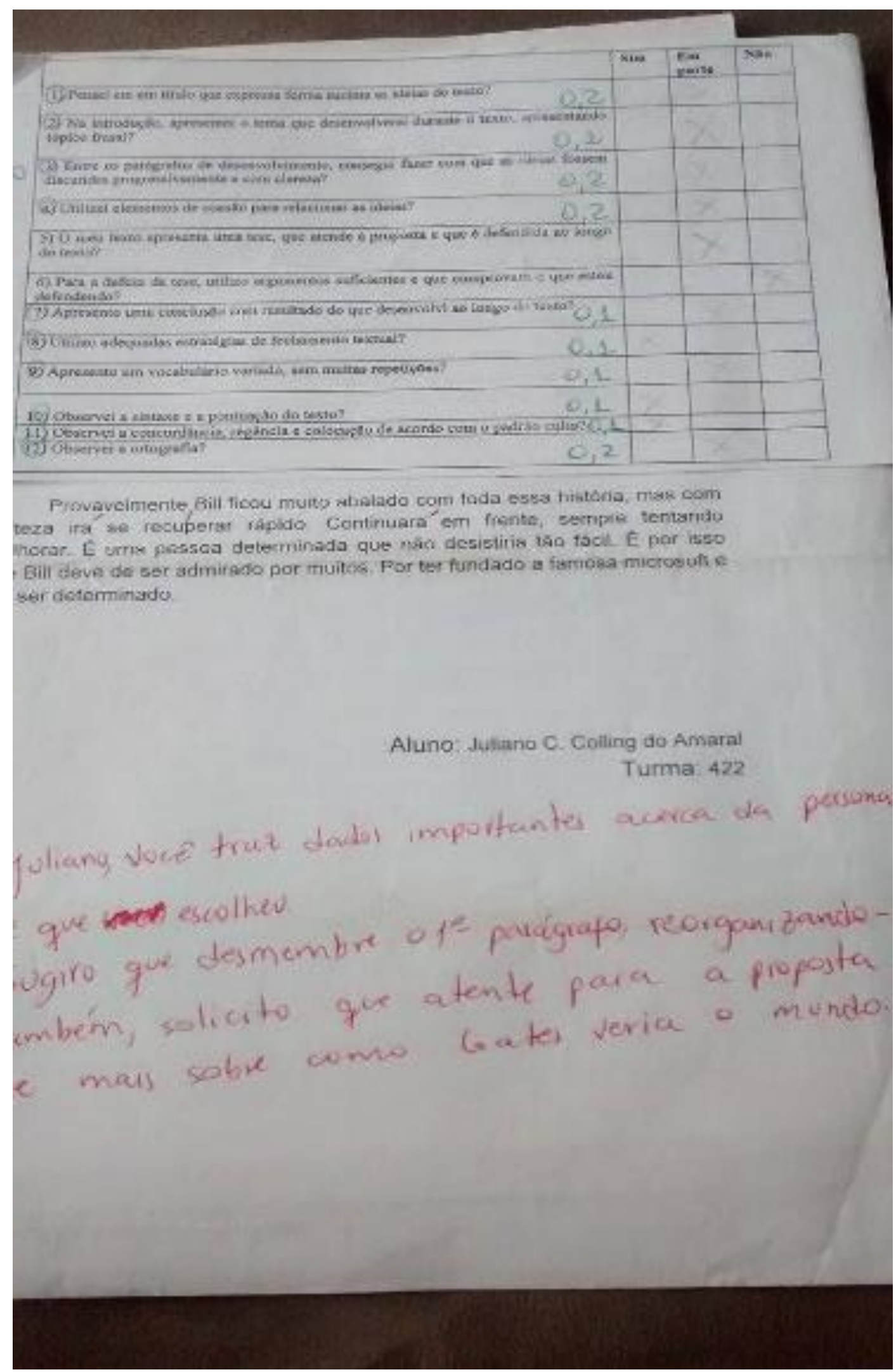

Imagem 2- Exemplar de texto recebido pelos alunos para realização da segunda versão 
Na imagem 2, há os critérios de avaliação, o texto do aluno, correções gramaticais ao longo do texto e orientações para a reescrita.

Para finalizar essa seção, cabe tratar do trabalho com as questões gramaticais. Pode-se afirmar que houve muitas dificuldades em abordar uma gramática reflexiva, mas acredita-se que é imprescindível o professor mostrar ao aluno que a gramática não funciona isoladamente, mas que funciona nos textos, nos gêneros que circulam pela sociedade.

\section{PONTOS CONVERGENTES: RELAÇÃO TEORIA-PRÁTICA}

Inicialmente, é considerável tratar da questão da concepção de linguagem utiliada durante o estágio. Percebeu-se que a visão interacionista da linguagem é uma concepção eficaz que contribui para o bom aprendizado de línguas visando à interação entre as pessoas.

Sobre a escrita como processo, ao longo do estágio, constatou-se que realmente é uma proposta adequada a de Soares (2009) ao apresentar estágios para a produção escrita, pois possibilita o estudo do gênero, a produção e a reescrita.

Durante a pré-leitura, o aluno é instigado a pensar sobre o que será escrito na sua produção. É o momento de contextualização, que é muito importante, pois acredita-se que a produção de texto deva sempre partir de um contexto específico, para que o aluno possa compreender que sua produção tem um propósito social definido.

$\mathrm{Na}$ atividade de escrita, o aluno pode organizar as ideias que teve acesso na pré-leitura e, por fim, na reescrita, o estudante tem a oportunidade de repensar sobre a sua prática estando diante do feedback do professor. É na reescrita que o aluno pode aperfeiçoar a sua produção. Aqui cabe ressaltar a importância dessa fase na atividade com produção escrita que teve na prática relatada, pois os textos dos alunos já eram bastante eficientes e, na reescrita, se tornaram melhores. Ainda sobre a reescrita, pensa-se que o professor deva, antes de solicitar a refacção, deixar claro os objetivos de se fazer tal atividade e os benefícios, pois o estagiário foi questionado pelos alunos do porquê reescrever um texto.

Nessas produções escritas dos alunos, é importante que o professor solicite gêneros textuais que estão no cotidiano dos educandos. Acredita-se que o trabalho com gêneros textuais torna-se relevante, porque o estudante pode perceber a diversidade e particularidades das produções escritas que estão na sociedade e mais do que isso, que esses gêneros têm uma função sociocomunicativa. Essa abordagem, portanto, abrange um contexto, que como afirmado anteriormente, é indispensável à produção textual.

Para deixar claro essa questão do contexto, salienta-se que Fuzer e Cabral (2010) afirmam que, em uma abordagem funcionalista da linguagem ${ }^{2}$, devido à relação íntima entre texto e contexto, os leitores podem prever o que está por vir no texto. Ainda, elas afirmam que dependendo do contexto de situação ${ }^{3}$ em que os enunciados são usados, diferentes leituras são possíveis. Isso acontece, pois saber 
onde o texto circula é essencial para a compreensão das ideias. Além disso, pensase que ter em mente o meio de circulação no momento de produzir um texto é necessário para se pensar na linguagem a ser utilizada.

Sobre a argumentação, não há dúvidas de que é indispensável nas aulas de Língua Portuguesa, pois a utilizamos no cotidiano e a argumentação começa a ser desvendada logo na infância, quando a criança, à sua maneira, defende seus interesses diante de outros sujeitos. Ao longo da vida, há um processo argumentativo e, acredita-se que é no Ensino Médio que os professores devem intensificar o trabalho com os gêneros argumentativos. Mas salienta-se que, embora não tenha sido trabalhado no estágio com a oralidade, os professores devem abordar em suas aulas de Língua Portuguesa também os gêneros orais que utilizem a argumentação.

Para unir essas produções dos alunos e possibilitar a autorreflexão, o portfólio é um importante instrumento. No referido estágio, percebeu-se que realmente possibilita os alunos refletirem sobre a sua produção e entenderem também que a produção escrita deve ser um processo.

Além desse trabalho, no estágio, foi trabalhado com as questões gramaticais e notou-se que a teoria de Travaglia é muito relevante, pois o aluno deve entender que a gramática, a produção textual e a leitura são um todo que funcionam ou devem funcionar juntos. Não se deve estudar a gramática com frases soltas, descontextualizadas, pois ela não funciona fora de um contexto, fora de um texto.

\section{CONCLUSÃO}

Diante deste trabalho, pode-se concluir, principalmente, que a produção escrita deve ser entendida como um processo. Tanto alunos como professores devem compreender isso, pois, assim, as atividades de produção de texto se tornam mais consistentes.

Além disso, é importante frisar que o estudante precisa saber defender seus pontos de vista, saber organizar suas ideias, ter conhecimento do que irá argumentar e saber se expressar de forma eficiente, bem argumentada o que pensa. Também cabe salientar que a argumentação desenvolve o senso crítico do estudante.

É necessário, ainda, destacar que trabalho com a reescrita e produção do portfólio torna-se importante na sala de aula, pois possibilita os alunos refletirem sobre as suas produções, podem também compreender como foi o seu processo de produção de textos, como foi a evolução.

Por fim, acredita-se que o professor de Língua Portuguesa deva refletir, constantemente sobre a sua prática docente, pesquisar sobre as teorias existentes, aplicá-las e perceber o que é válido e o que não é. Ao final desse estágio, com este trabalho, pensa-se, mais do que nunca, que o professor deve ser um indivíduo que está constantemente se aperfeiçoando com novas técnicas, novas teorias e refletindo sobre a sua prática. 


\section{Notas}

${ }^{1}$ A escola em questão é o Colégio Técnico Industrial da Universidade Federal de Santa Maria e a turma um segundo ano de Mecânica Integrada ao Ensino Médio.

${ }^{2}$ Essa abordagem é a Gramática Sistêmico-Funcional de Halliday e Matthiessen (2004) e que as autoras adaptam para a língua portuguesa. Apenas foi trazida tal teoria nessa seção para explicar o porquê que se pensa que sempre se deve pensar em um contexto, seja na produção escrita, seja no ensino de gramática.

${ }^{3}$ Contexto de situação é uma terminologia da Gramática Sistêmico-Funcional que consiste no ambiente imediato no qual o texto está de fato funcionando (FUZER; CABRAL 2010).

\section{Referências}

ABREU, A. S. A arte de argumentar: gerenciando razão e emoção. 11. ed. Cotia/São Paulo: Ateliê Editorial, 2008.

BERNARDO, G. Educação pelo argumento. Rio de Janeiro: Rocco, 2000.

BEZERRA, M. A. Por que cartas do leitor na sala de aula In: BEZERRA, Maria Auxiliadora; DIONISIO, Angela Paiva; MACHADO, Anna Rachel (Org.). Gêneros textuais e ensino. 5. ed. Rio de Janeiro: Lucerna, 2010. p. 208-216.

BRASIL, Ministério da Educação e Desporto. Orientações curriculares para o Ensino Médio: Linguagens, códigos e suas tecnologias. Brasília: SEF, 2006.

CUNHA, D. A. C. O funcionamento dialógico em notícias e artigos de opinião. In: BEZERRA, Maria Auxiliadora; DIONISIO, Angela Paiva; MACHADO, Anna Rachel (Org.). Gêneros textuais e ensino. 5. ed. Rio de Janeiro: Lucerna, 2010. p. 166-179.

DOLZ, J.; NOVERRAZ, M.; SCHNEUWLY, B. Sequências didáticas para o oral e a escrita: apresentação de um procedimento. In: DOLZ, J.; SCHNEUWLY, B. Gêneros orais e escritos na escola. Campinas: Mercado de Letras, 2004. p. 95-128.

FUZER C.; CABRAL, S. R. S. Introdução à Gramática Sistêmico-Funcional em língua portuguesa. Santa Maria: UFSM, CAL, DLV, NELP, 2010.

GERALDI, J. V. (Org). O texto na sala de aula. São Paulo: Ática, 1997.

HALLIDAY, M. A. K; MATTHIESSEN, C. M. I. C. An introduction to functional grammar. 3. ed. London: Arnold, 2004.

MARCUSCHI, L. A. Gêneros textuais: constituição e práticas sociais. São Paulo: Cortez, 2008.

MOIRAND, S. Les índices dialogiques de contextualisation dans La presse ordinarie. Cahiers de praxématique, 1999. 
MOTTA, V. R. A. Noticing e counsciousness-raising na aquisição da escrita em língua materna. 2009. Tese (doutorado em Letras) - Universidade Federal de Santa Maria, Santa Maria, 2009.

SOARES, D. A. Produção textual e revisão textual: um guia para professores de Português e de Línguas Estrangeiras. Petrópolis, RJ: Vozes, 2009.

TRAVAGLIA, Carlos Luiz. Gramática e Interação: uma proposta para o ensino de gramática. 11. ed. São Paulo: Cortez, 2006.

\section{Para citar este artigo}

CRUZ, Lucas Saldanha da. O ensino de língua portuguesa e suas abordagens: uma relação teoria e prática. Miguilim - Revista Eletrônica do Netlli, Crato, v. 6, n. 1, p. 24-37, jan.-abr. 2017.

0 autor

Lucas Saldanha da Cruz é formado em Letras-Português pela Universidade Federal de Santa Maria, estudante de Mestrado em Estudos Linguísticos pela mesma instituição, professor da rede particular de ensino e de cursos preparatórios. 